\title{
Book Review: What's in a Name?
}

\section{Citation}

Jonathan Zittrain, What's in a Name?, 55 Fed. Comm. L. J. 153 (2002) (reviewing Milton L. Mueller, Ruling the Root: Internet Governance and the Taming of Cyberspace (2002)).

\section{Published Version}

doi:10.2139/ssrn.350560; http://www.fclj.org/wp-content/uploads/2013/01/zittrain.pdf

\section{Permanent link}

http://nrs.harvard.edu/urn-3:HUL.InstRepos:12211480

\section{Terms of Use}

This article was downloaded from Harvard University's DASH repository, and is made available under the terms and conditions applicable to Other Posted Material, as set forth at http:// nrs.harvard.edu/urn-3:HUL.InstRepos:dash.current.terms-of-use\#LAA

\section{Share Your Story}

The Harvard community has made this article openly available.

Please share how this access benefits you. Submit a story.

\section{Accessibility}




\section{BOOK REVIEW}

\section{What's In a Name?}

Ruling the Root, Milton L. Mueller, Cambridge, Mass.: MIT Press, 2002, 301 pages.

\section{Jonathan Zittrain*}

In the spring of 1998, the U.S. government told the Internet: Govern yourself. ${ }^{1}$ This unfocused order-a blandishment, really, expressed as an awkward "statement of policy" by the Department of Commerce, carrying no direct force of law-came about because the management of obscure but critical centralized Internet functions was at a political crossroads.

In Ruling the Root, ${ }^{2}$ Milton L. Mueller thoroughly documents the colorful history both before and after this moment of inflection, and gives a fair appraisal both of the interests at stake and of the ways in which those interests have influenced the course of that history. It is clear that he laments the domination of latter parts of the tale by the Internet Corporation for Assigned Names and Numbers ("ICANN"), a California nonprofit created expressly to answer the U.S. government's 1998 challenge. Mueller finds ICANN to be at best a rigid, bureaucratic clamp on the innovation that had previously marked the Internet space, and at worst an instrument of old-guard "corporatist" interests bent on maintaining (or replicating from other fields such as broadcast and telephone) artificial scarcity of resources for the purpose of concentration of control. The questions left open by Mueller's inquiry are important, and to understand both these and the depth of Mueller's frustration with

* Jack N. and Lillian R. Berkman Assistant Professor for Entrepreneurial Legal Studies, Harvard Law School. I thank Megan Kirk for research help, Molly S. Van Houweling for helpful suggestions, and Ben Edelman for line edits.

(C) 2002 Jonathan Zittrain.

1. Mgmt. of Internet Names and Addresses, 63 Fed. Reg. 31741 (June 10, 1998), available at http://www.ntia.doc.gov/ntiahome/domainname/6_5_98dns.htm (Last visited Sept. 24, 2002)

2. Milton L. Mueller, Ruling the Root (2002). 
ICANN, it helps to reflect on the unusual way in which coordination of the global Net came about.

The Net had developed as a means of sharing information among anyone who could hew to its protocols, and the authors of those protocols were computer scientists and engineers of various stripes, engaged in a loose collective enterprise funded without expectations of direct profit by their commercial and nonprofit employers, and by the U.S. National Science Foundation and Department of Defense. Loose, yes, but also with elements of self-governance: The engineers who worked on Net protocols came to know each other, to name themselves the Internet Engineering Task Force ("IETF"), to select leaders from among themselves, and to agree upon processes by which to reach closure on contested issues so that the network could continue to develop. "Rough consensus and running code" was the guiding creed: the latter provided an objective metric by which to evaluate competing technical protocols; the former provided a reminder that since many advances in a given area of internetworking required everyone using that subsystem to agree upon a particular protocol, less than unanimity on its details ought to be enough to constitute "agreement" for all concerned. Moving forward was more important than moving forward perfectly.

Mueller refines this account by noting tensions between the rank-andfile engineers of the IETF and those who emerged as their leaders. Among the alphabet soup of organizations involved in Internet engineering through the 1990s with overlapping sets of participants, the Internet Architecture Board ("IAB") and the Internet Society-intended in their own respective ways to serve as political or legal leadership for the informal IETF collective-quickly ran into internal challenges to their legitimacy generally, and methods of governing themselves specifically. ${ }^{5}$ Mueller highlights here what he calls the "technical cadre's allergy to democratic methods and public accountability,", and suggests that this had a significant influence on ICANN's later formation, and he is right.

Democratic or not, the IETF standards process has been responsible for the spectacularly successful bedrock elements on which the Internet functions, ranging from core logical layer Transmission Control

3. See Internet Engineering Task Force, The Tao of IETF: A Novice's Guide to THE INTERnET ENGINEERING TASK ForCE RFC 3160 (Aug. 2001), at http://www.ietf.org/tao.html.

4. Scott Bradner, The Internet Engineering Task Force, in OPEN SourCES: VoICES FROM THE Open SOURCE REvolution (Mark Stone et al. eds., 1999), available at http://www.oreilly.com/catalog/opensources/book/ietf.html.

5. Mueller, supra note 2, at 94-98.

6. Mueller, supra note 2, at 97. 
Protocol/Internet Protocol ("TCP/IP") networking to e-mail interchange to clock synchronization. Each of these reflects the desire to have all networked entities interacting according to the same protocols-enabling different brands and platforms of computers to communicate with each other without bulky translation software or gateways.

In addition, certain elements of the Internet created through IETF processes-most notably, its naming and numbering schemes, which suppose the existence of unique identifiers such as www.cnn.com and 128.36.0.19 distributed among various Internet users-require some form of central coordination, if only to ensure that uniqueness. Without central coordination, two different Net destinations might advertise themselves as possessing identical numeric or named identities, and data packets would be misrouted on their way across the Net's topography to a particular destination. The coordination could, in theory, take the simple form of a commonly shared list of those identities already "taken" by someone, and indeed the "first-come, first-served" nature by which many domain names are available to registrants reflects that idea. But whoever maintains a common list typically has, as a technical matter, the ability simply to change the list-perhaps delisting a name whose registrant has fallen behind in yearly maintenance payments demanded by the list holder, or reassigning a name previously reserved for one registrant to another because that other has made a claim of right.

When a commons is large and the decent pastures well distributed across it, there's little reason for shepherds to fight for turf. But if there's any sense of scarcity - of the commons' contents generally, or its "good areas" specifically_there must be a way of forestalling or resolving a stampede. By 1997, the Internet's supply of "good" names was thought to be drying up. Worse, certain good names were thought to be in the wrong hands. As a Web presence became a near-necessity for large businesses, the realization that corporate marquee names such as avis.com and mcdonalds.com already had been reserved, first-come, first-served, by individuals with no connections to the Avis car rental company or McDonald's hamburger restaurants caused severe and consistent consternation among famous trademark holders.

How then to create new, fertile turf such as .biz and info when corporate interests-including those who operated the Internet service providers ("ISPs") who together are the Internet's pathways-already had their hands full attempting to claim control over their corporate brand names within .com, .net, and .org?

Further, through a Byzantine tangle of cooperative agreements offered by the National Science Foundation ("NSF"), the purpose of which 
was to promote the development and use of networks, one companyNetwork Solutions - was by 1995 the registration and renewal authority for all domain names in .com, .net, and .org, sitting astride a booming and essentially monopolized business. Network Solutions also had become the technical operator of the "A root"- the "list of lists"- the authoritative set of pointers to all sublists of "second-level" domain names, i.e., those ending in .com, .au, and any other suffix. As Mueller documents, Network Solutions had made it clear to Jon Postel-a researcher and IETF leader who by acclamation among the original Net designers was the "Internet Assigned Numbers Authority" with supposed custody over the root-that Network Solutions would not add to its list of lists without direction from the National Science Foundation, something NSF had never done or previously been asked to do.

Without cooperation from Network Solutions and commercial ISPs, Postel and his colleagues within the IETF could not readily expand the ever-more-precious domain name turf, and they realized that the issue had dimensions well beyond the technical. They convened an "International Ad Hoc Committee" to devise a much more formal process for setting up turf rules. Network Solutions refused to acknowledge the IAHC's authoritywhich was, to be sure, self-proclaimed-sparking a constitutional crisis as stark as it was abstruse. At Postel's request, eight of the Internet's thirteen name root servers, each previously a replica of the "A root" and thus collectively the source of answers for questions like "who manages the numeric destinations of names ending in .com," were adjusted by their operators-themselves doing work thanks to a handshake rather than a contract - to retrieve their domain name data from Postel's own root server, a test that might demonstrate that control of the domain naming system could be wrested from Network Solutions. ${ }^{7}$

"We were concerned," said an understated spokesperson for Network Solutions. "It points to the instability of a system run by volunteers." Network Solutions wasn't the only one concerned. The National Science Foundation, not wanting to take on any role which would require it to pick winners and losers in anything other than the allocation of grants, passed the tangle to a unit of the Department of Commerce: the National Telecommunications and Information Administration ("NTIA"), whose charter is "to spur innovation, encourage competition, help create jobs and provide consumers with more choices and better quality

7. See Dominic Gates, Culture Clash in the Root Zone: Should Jon Postel Be the Master of Your Domain?, PreText Magazine, March 1998, at http://www.pretext.com/ mar98/features/story4.htm (last visited Sept. 24, 2002).

8. Id. 
telecommunications products and services at lower prices." ${ }^{\circ}$ NTIA's staff began to talk to anyone who appeared to be related to the conflict, and over time, with the help of seemingly endless worldwide consultations with interested technical, business, and political camps, hammered out the "White Paper" statement of policy that said, in effect, govern yourself. ${ }^{10}$

This story emphasizes that there were competing claims to ownership of the root and no easy way to choose among them, substantively or procedurally. And, despite the U.S. government's desire to back away from any public sector management of domain names specifically and perhaps the Internet generally, the White Paper by no means was a complete abdication. After all, the government simply could have let private parties in a position to assert control of the root negotiate or battle it out, perhaps asking courts to require desired action or forbearance from rivals. Instead, the White Paper contained important caveats that ensured that the Commerce Department could choose, and therefore shape, the nominally private authority that would answer its call. The NTIA's actions eclipsed former efforts at resolution; the IAHC was dissolved and the "memorandum of understanding" it had generated lay fallow in its repository at the International Telecommunications Union."

It's not clear what Mueller thinks of this strategy, in part because he seems ambivalent about the need for central coordination of domain names in the first instance. After several pages of analysis, Mueller punts on the issue of "alternative roots," by which ISPs-and, in some implementations, their respective users-could be encouraged to determine whose root among multiple ones would provide direction regarding the sources of authoritative data about who manages .com, .net, etc. He sees no easy way to choose between the convenience of a single point of coordination inherent in a natural monopoly of the root and the benefits of fostering a competitive regime in which different root operators are encouraged to sprout, possibly fragmenting the Internet experience from one user to the next. $^{12}$ This equivocation leaves open the question of whether the U.S. government should have simply walked away rather than prodding ICANN into existence. I believe alternative roots are an awful idea, for many of the reasons articulated by the IETF/IAB in a document released perhaps

9. See NTIA Charter, at http://www.ntia.doc.gov/ntiahome/ntiafacts.htm (last modified May 6, 1998).

10. See Mgmt. of Internet Names and Addresses, 63 Fed. Reg. 31741 (June 10, 1998), available at http://www.ntia.doc.gov/ntiahome/domainname/6_5_98dns.htm.

11. See gTLD-MoU: Generic Top Level Domain Memorandum of Understanding, at http://www.gtld-mou.org (last updated Aug. 12, 1999); IAHC: Internet International Ad Hoc Committee, at http://www.iahc.org (last updated May 26, 1997).

12. Mueller, supra note 2, at 50-56. 
specifically (and therefore politically) to bolster ICANN's

authority, ${ }^{13}$ and, given that nothing legally prohibits their deployment, the market has so far agreed. ${ }^{14}$ It's clear Mueller has given much thought himself to the issue. His account would benefit, and perhaps at some point will be augmented, by a clear statement articulating whether he believes a central coordinating function in the public interest is needed, and what role, if any, the U.S. government should have played, or should continue to play, in its shape.

Similarly, Mueller's views on the alternatives to ICANN's structure remain comparatively shrouded, if indeed he believes there should be any central coordinating body operating in the public interest. He points out the flaws in arguments that ICANN should be run like the IETF, for example, on lines of informal consensus. While this miraculously seems to work for Internet architectural questions with no obvious political or financial winners and losers, the ineffectiveness of good faith and handshakes all around to resolve domain name disputes is precisely what set Postel to the strategy of isolating domain name issues within a different kind of organization.

I attended several meetings of the International Forum on the White Paper ("IFWP") in the aftermath of the U.S. government's call for a new nonprofit domain name authority. Mueller well describes the heady confusion of the summer of 1998 as Postel, Network Solutions, and others vied to gather the political momentum to found "Newco." 15 Professor Tamar Frankel of Boston University had been asked to chair the initial meetings by the shifting set of those organizing them, and at her insistence the IFWP participants emphasized those points on which they could find consensus - which, unsurprisingly in retrospect, turned out to be a feelgood laundry list of rights and benefits that did little to suggest how to resolve actual conflicts. Network Solutions, seeing Postel, independent of the IFWP, issue iterative drafts of proposed by-laws concrete enough to form the basis of a new organization, finally simply drafted its own "community consensus" by-laws, but as Mueller points out, consensus was nearly impossible to gauge. The best one could do was poll to see if more than a handful of people present at one of the IFWP meetings objected to a particular idea.

One of the more specific ideas in play was that of a global electorate that could populate some or all of Newco's board. Postel, and apparently

13. See Internet Architecture Board, iaB Technical Comment on the Unique DNS RоOT RFC 2826 (May 2000), at http://ftp.ietf.org/rfc/rfc2826.txt.

14. See http://www.new.net for one such provider.

15. MuelLER, supra note 2, at 175-180. 
most others identified with the IETF (those described in Mueller's accurate if valenced terms as "allergic to democracy") were indeed averse to such an idea. He and they chafed at the notion that anyone prodded into filling out a voter registration form could weigh in equally on what was still largely a technical matter, and feared capture by a particular interest that might orchestrate a voting campaign. Network Solutions, with every incentive to freeze the status quo as much as possible, liked the idea of a powerful electorate whose cumbersome approval would be needed for any major changes.

As Mueller documents, under pressure from the U.S. Commerce Department the final draft of ICANN's bylaws contained a commitment to an electorate choosing half the board's seats. ${ }^{16}$ I participated in the "membership advisory committee" later chartered by ICANN to turn that commitment into practice. I shared Mueller's view that of all the interests vying for representation, it was the average Internet end user who stood to be shortchanged. Those of us who were on the committee embraced the task of designing a process that would allow one person, one voteultimately a check on the board's power by a distributed group of selfidentified, concerned Internet users who might be roused to respond to important issues or abuses of power.

It is hard to discern whether Mueller believes the ICANN election of 2000 was a success. He notes, perhaps approvingly, that the victors were themselves critics of ICANN. ${ }^{17}$ Africa's seat on the board was chosen among 130 voters continent-wide; North America's by $3,449 .{ }^{18}$ Asia witnessed 17,745 registered voters, by some accounts thanks to a nationalistic competition between China and Japan that included thousands of attempted (and failed) last-minute registrations from the People's Republic (The Japanese candidate won in a landslide.). ${ }^{19}$

Some would view these sorts of results as healthy electioneering, or at worst each region simply reaping results that are, among other things, functions of its own level of voter apathy, bias, or sellout. If ICANN's elected leadership turns out to be ineffective or otherwise poor-well, at least the blame rests on everyone, since everyone potentially could have registered and voted. Mueller seems silent on the question. My own view has become increasingly skeptical, even as some of the actions taken by

16. Id. at 184 .

17. Id. at 198-201.

18. See ICANN, at http://www.election.com/us/icann/icannresult.html (last visited Sept. 24, 2002)

19. See id.; see also Nominating members-nationalistic competition, NAIS (2001), at http://www.naisproject.org/report/final/2.2.2.2.3.shtml (last visited Sept. 24, 2002). 
ICANN illustrate obvious flaws in its current policies (and perhaps therefore its leadership), such as retaining a dispute resolution process with manifest, well-documented structural defects; ${ }^{20}$ refusing to release to one of its own elected directors, without added promises of confidentiality, documents to which the director is statutorily entitled; ${ }^{21}$ and failing to curb registrar "slamming" practices. ${ }^{22}$ Individuals delegate to their governments a host of matters to decide, and in international arenas we see coordination through treaty and sometimes further through intergovernmental organizations whose members are governments themselves. Mueller appears to agree that ICANN in its current incarnation, despite its formal incorporation as a private nonprofit, does not stray far from the desires of its most powerful stakeholders, including the U.S. government and staff of the European Commission. Wide-open elections could result in a board far more combative with those interests, but that is separate from making the case that such a board would be any more in line with important goals than the one that exists now, or for that matter more in line with whatever the old-guard Internet engineering community might have preferred. Mueller's project, as an arm's-length institutional analysis, leaves open the normative questions of what policies are best for the Net-and what kind of organization would best be able to pursue them. The closest he comes to such questions is when he notes that the interests behind famous trademarks have gotten much of what they desired from the process, which was more than they were in many cases legally entitled to before ICANN came into existence. For my part, I doubt that an undefined global electorate can be of much help-it is at once too weak and dispersed to serve as a check on board misconduct, while enabling easy domination by an intense voter registration campaign organized by a narrow interest. It is difficult enough to get voters at large to concern themselves with electing heads of state, much less the board members of a difficult-to-understand, technically oriented organization. Hence the appeal of a merit selection trustee model-perhaps chosen in part by government representativesthat Mueller eschews.

20. See Michael Geist, Fair.com? An Examination of the Allegations of Systemic Unfairness in the ICANN UDRP, 27 BROOK. J. INT'L. L. 903 (2002); Michael Geist, Fundamentally Fair.com? An Update on Bias Allegations and the ICANN UDRP, at http://aix1.uottawa.ca/ geist/frameset.html (last visited Sept. 24, 2002).

21. See Auerbach v. ICANN, No. BS 074771 (L.A. Super. Ct. Aug. 1, 2002), available at http://www.eff.org/Infra/DNS_control/ICANN_IANA_IAHC/Auerbach_v_ICANN/ 20020807_auerbach_judgment.pdf.

22. See Thomas C. Greene, Verisign Accused of DNS Slamming, THE REGISTER, Mar. 26, 2002, at http://www.theregister.co.uk/content/6/24577.html. 
For these reasons I agree with Mueller's conclusion that ICANN as it stands, especially on the cusp of eliminating its fascinating if unsatisfying global membership, is not nearly as sui generis an organization as many believe, and that it ultimately is an undemocratic creature largely comprising the government and economic interests it is perhaps meant to transcend. Yet I am not sure this is as bad as Mueller suggests, and to explain why, it is helpful to pause and to question the extent to which domain names are important to the Internet's future.

Once immersed in the intricacies of the story of ICANN, one might find it interesting enough in its own right, as simply a study of struggles among oft-colorful personalities and the institutions and groups in which they participate. But Mueller has sought to go beyond the mere melodrama innate to the alliances and rivalries among a complex set of groups and people, and additionally to spell out why this matters. This has been a persistent challenge for the civil society groups attempting to raise an alarm about ICANN to the broader public, and one that may not be easy to meet on its own terms. The most common marcher in the parade of horribles offered up to justify broad concern about domain names and ICANN is that control over the root-and then through a rather complicated strategy of leverage, control over the assignment of domain names generally-can ultimately become control over what people can say on the Internet itself, a set of limits imposed wholly apart from any one sovereign's laws.

Mueller persuasively identifies the deployment of the "uniform dispute resolution policy" ("UDRP") for holders of names within the most common generic top-level domains as one of ICANN's most important activities since its inception. And, to be sure, the UDRP creates "mechanized rights" by which a domain name holder can be quite summarily dispossessed of her name if an arbitrator chosen by a challenger (or, in rarer instances, a panel of arbitrators) finds the name to have been registered and used in bad faith, contrary to some right of the challenger, and with no legitimate right or interest in the name by the registrant. While he traces a number of attempts (by the World Intellectual Property Organization, in particular) to broaden the scope of challengers' powers under the UDRP, one is still left with the question of just how much domain names matter. That some fetch high prices alone shows that many matter in the pecuniary sense, but the civil society groups are less interested in creating a smooth market of entitlements-and Coase, after all, might figure that initial allocations aren't of great import so long as the names are readily and reliably alienable ${ }^{23}$ - than they are in tying ICANN's powers to

23. See R. H. Coase, The Problem of Social Cost, 3 J. LAw \& Econ. 1 (1960). 
the prospect of a diminution of free speech, or a launching pad for political control. This is a harder case to make; one can create a Web site without the use of a domain name at all by simply advertising its numeric IP address, and the advent of search engines assures some potential to get one's word out without having to have a short, mnemonic (or, put more precisely, brand-associated) domain name.

Mueller seems to concede as much, instead seeking to focus attention on domain name battles as harbingers of the Internet's future, much as the importance of the health of the spotted owl is primarily grounded in its claimed role as a bellwether for the health of an entire forest. "The dirty little secret of the whole affair is that domain names are not nearly as valuable or as important as the new institutional regime would like to pretend they are." ${ }^{24}$ Instead, writes Mueller, they are the front line of a proxy war which is intended to set "precedents for the treatment of the entire online economy." 25 This is a difficult claim to advance since it is by its nature sweeping while speculative-and because the way in which the war over domain names is won is, as Mueller emphasizes, through control over the root. As a technical matter, control over the root means control over domain names-no more and no less, unless other matters can be brought to heel through withholding or otherwise controlling domain names themselves. For example, those who dislike a service such as Napster, even if they controlled the root, could at the realistic extreme merely force the elimination of www.napster.com as a domain name, a victory both extremely unlikely and, should it ever happen, surely Pyrrhic. Demanding accurate WHOIS data-information on domain name registrants that is collected (and rarely verified) from registrants when they ask for a new name-might tie individual identities to particular Web site name registrations, but this is a staggeringly far cry from an "Internet driver's license," especially since most Internet users do not possess or need domain names, and many individuals who make available Web sites do so through free hosting services that, in the absence of billing verification, themselves do not readily know who their customers are. One is left having to defend the surely narrower importance of domain names themselves, or take on the difficult if interesting task of identifying the ways in which other areas of Internet standards-for example, areas that remain within the IETF-are being influenced by concerns other than engineers' purportedly neutral desires to simply get packets from one place to another as efficiently as possible. The story of ICANN may not shed a particularly bright light on that inquiry.

24. MuELLER, supra note 2, at 227.

25. Id. at 228. 
I maintain that domain names serve a patently valuable but ill-fitting directory function ${ }^{26}$ that may be eclipsed by another naming scheme, one without dashes and dots. ${ }^{27}$ The scheme might come from browser manufacturers encouraging their users to enter simple words-and treating those words as a search for which only one result will be returned. Then those who write the browsers, or those to whom they pass the words for search results, will be in a position to say which names lead to which destinations. Whether or not such a shift takes place, to entertain the idea is to realize that the idiosyncratic position in which we found the rootconclusively owned by no one, and with all hands more or less agreeing that it should be operated according to varying notions of the public interest-likely will not be repeated for newer Internet developments.

The IETF's "requests for comments" ("RFCs"), which outline key functions of the Internet, are now firmly asserted as copyrighted by the Internet Society. ${ }^{28}$ The copyright is deployed as a flavor of "copyleft," meaning that it is used for the purpose of ensuring the widespread availability of the standards, preventing their proprietization by any particular party. ${ }^{29}$ The intellectual property behind RFCs is thus held in trust by the Internet Society-the IETF umbrella group which still retains some influence over ICANN, and which at this writing has been tentatively selected by ICANN to run the .org registry, providing an anticipated needed infusion of cash to the organization. ${ }^{30}$ In other words, there is no doubt that the Internet Society "owns" its RFCs, and thus no battle is to be waged over who will rule them. There is only the question of whether the world at large will pay heed to them as they are published-since an RFC is not self-enforcing.

Innovations by private firms are either controlled in the traditional way through various flavors of intellectual property asserted by those firms, or shepherded through complicated "open" consortia such as Sun's "Java Community Process" program. ${ }^{31}$

26. Id. at 105 .

27. See Jonathan Zittrain, Keyword: Obsolete, Wired, September 1998, at http://www.wired.com/wired/archive/6.09/netizen.html?pg=5.

28. See The Internet Society, 30 Years of RFCs 18 (April 7, 1999) at http://ftp.rfceditor.org/in-notes/rfc2555.

29. See Free Software Foundation, InC., What is Copyleft? at http://www.gnu.org/copyleft/copyleft.html (last updated July 29, 2002).

30. See .org Reassignment: Preliminary Staff Report on Evaluation of the Proposals for Reassignment of the .org Registry at http://www.icann.org/tlds/org/preliminary-evaluationreport-19aug02.htm (last visited Sept. 24, 2002).

31. See The Java Community Process at http://www.jcp.org/ (last visited Sept. 24. 2002). 
None of these is a model of one-person, one-vote democracy independent of geographic sovereigns, and perhaps for good reason-I have argued such democracy is as platonically elusive as the alternative vague "community consensus" process that Mueller rightfully discounts.

While it has succeeded in the narrow sense that the domain name and numbering system remains more or less stable and secure, I think it is increasingly clear that the ICANN experiment has failed to show a functioning, sustainable middle path between public and private governance of a common but previously ambiguously controlled resource. We pay the price now in terms of stagnation of the domain name space and function, the transfer of names under the UDRP that might arguably be best left to their original registrants, and lower but still-inflated costs for domain name registration - the odd rental of names for roughly $\$ 15$ per year per name, completely unhinged from anything reflecting underlying costs, much of which ironically revolve around processing invoices. The initial mistake in these matters may well have been the National Science Foundation's decision to permit Network Solutions to begin charging individual customers for names, rather than simply subsidizing the function as a government contribution to a well-running Internet, or in allowing the price ceiling to be determined by an annual fee rather than by a one-time initial registration charge, perhaps with further charges to process requested changes to existing registrations such as transfers to new holders or domain name hosts.

All told, this is a comparatively low price to pay. To be sure, the Internet's future is indeed in question, and many indications point to a Net much less free-as in free speech, not free beer-than the one we enjoy today. The movement of data likely will be much more tightly surveyed and controlled, assisted by changes to network architecture and to the consumer personal computer itself. A battle is now under way to determine whether wireless Internet connections can be managed through a rough technical spread spectrum anarchy, or whether government monopoly spectrum carveouts will remain the order of the day.

The existence of ICANN does nothing to further dampen the Internet's uncertain future in these areas, except perhaps to demonstrate the fact that as a global polity, Internet users are not capable of governing themselves. Not, I think, because the root has been appropriated by the usual suspects, but rather because cyberspace on its own terms has simply never found its identity as a distinct space with its own values and leaders. This should not come as a surprise except to the early Internet pioneers who had reason to think it would indeed be a separate "cyber space," a community of avatars. Today it is, by American user demand at least, first 
a conduit for e-mail; second a source for news, weather, and other information; and distantly a shopping mall. ${ }^{32}$ Broadband deployment may change this, ${ }^{33}$ but to see individuals becoming content providers rather than simply shifting their television consumption to a digital pipe using TCP/IP will require at least both the development of innovative software around which communities can form, and a jumpstart to encourage participation in those virtual communities.

The key for the civic society promoter, in other words, is not in fighting over such things as domain names, the value of which has been belatedly identified as precious to powerful parties for reasons that bear little on civic values. The real challenge lies in maintaining an open Internet, with points of access and pathways that do not discriminate against particular users, programs, or data - and then developing paradigmaltering uses for that Internet that place news, weather, chat, and shopping into a comfortable background.

32. See Pew Internet and American Life Project, Daily Internet Activities (Dec. 2001) at http://www.pewinternet.org/reports/chart.asp?img=Daily_Internet_ Activities.jpg.

33. See John B. Horrigan \& Lee Rainie, The Broadband Difference: How Online Americans' Behavior Changes with High-Speed Internet Connections at Home, Pew Internet \& American Life Project, at http://www.pewinternet.org/reports/pdfs/PIP

Broadband_Report.pdf (last visited Sept. 24, 2002). 